\title{
Reducing energy consumption of air- conditioning systems in moderate climates by applying indirect evaporative cooling
}

\author{
Aleksandra Cichon $^{1, *}$, Anna Pacak $^{1}$, Demis Pandelidis ${ }^{1}$, and Sergey Anisimov ${ }^{1}$ \\ ${ }^{1}$ Department of Environmental Engineering, Wroclaw University of Science and Technology, 27 \\ Wyspiański st., 50-370, Wroclaw, Republic of Poland
}

\begin{abstract}
This paper investigates the potential of applying an indirect evaporative cooler for heat recovery in air conditioning systems in moderate climates. The counter-flow indirect evaporative heat and mass exchanger is compared with commonly used recuperation unit in terms of achieved energy. The performance analysis of the indirect evaporative exchanger is carried out with original $\varepsilon$-NTU-model considering condensation from treated air. It was found that the indirect evaporative exchanger employed as a heat recovery device, allows to obtain higher performance than conventional recuperator. Additional energy savings potential is related with utilizing the potential of water evaporation to pre-cool the outdoor air. It is also stated that there is a high potential of reusing condensate that forms in product channels of the indirect evaporative exchanger and in the vapour-compression unit and delivering it to the working part of the indirect evaporative exchanger.
\end{abstract}

\section{Introduction}

Nowadays, most of the air-conditioning (AC) systems are based on the conventional mechanical vapour-compression cooling technology which is driven by an electrical energy. Since the major part of the global electricity comes from fossil fuels, it causes the rising awareness of environmental and sustainability issues. One of the alternatives to the mechanical vapour-compression systems is the indirect evaporative cooling (IEC) process, based on the water evaporation $[1,2]$.

The IEC heat and mass exchanger in the counter-flow configuration, which is considered in this paper, is made of two types of channels (Fig. 1). First type of channel is the product channel, where the product airflow is delivered. In the second type of channel, the working channel, channel plates are covered with water which constantly evaporates into the working airflow. The process of evaporation results in decreased temperature of the plate that separates product and working channels, and this, in turn, allows to cool the product airflow which flows through the product channel $[3,4]$. Over recent years, the IEC was addressed in various studies in terms of different mathematical modelling, technical configurations or application in the AC systems. For example, Duan et al. [5] designed and tested a counter-flow regenerative evaporative cooling device. It was found that the studied

\footnotetext{
${ }^{*}$ Corresponding author: aleksandra.cichon@pwr.edu.pl
} 
regenerative evaporative cooling device was able to reduce cooling load by $53-100 \%$ and electrical energy consumption by $13-58 \%$ on annual basis. Porumb et al. [1] used multiannual weather data to compare air-conditioning system based on a conventional electric cooler and one consisted of an indirect evaporative heat exchanger. It was stated that yearly energy consumption of the evaporative cooling system was $80 \%$ lower than in case of conventional air-conditioning system. In terms of mathematical modelling, Chen et al. [6] presented an analytical model that considers condensation from product airflow. Studies were carried out for hot and humid climate conditions of South-East Asia. The annual simulations data were compared with field measurement at good agreement. Different computational model, considering condensation from product airflow, was developed by Cui et al. [7]. Based on the simulation for hot and humid climate conditions, it was found that the IEC exchanger, as a part of the air-conditioning system, was able to cover $47 \%$ of cooling load.

As presented above, the IEC technologies are gaining more interest, due to their high energy and cost savings potential under different climate conditions. An important aspect that should be addressed and analyzed is the possible application of IEC cooler for heat recovery in moderate climates. Nowadays, the most popular heat recovery technique in moderate climates is recuperation, in which the cooling process is limited by the exhaust airflow dry-bulb temperature. In compare, the IEC process is limited by the exhaust airflow wet-bulb temperature, which increases its energy performance. In this paper, the AC systems consisted of the heat recovery unit followed by a conventional vapour-compression device is proposed (Fig. 1). In this configuration, the outdoor air passes through product channels and then conventional vapour-compression cooler to be delivered to the conditioned space. Exhaust air from the conditioned space passes through the working channels and it is discharged outside the system. Different issues of IEC operating as a heat recovery device are addressed in this research. Firstly, the possibility of water condensation in the product channel due to the low temperature of the working airflow and its influence on the IEC exchanger performance. Secondly, the critical aspects of the unit operating under different inlet airflow parameters are studied. Additional comparison is made in order to evaluate the energy and water savings in the AC systems with the IEC exchanger and conventional counter-flow recuperation unit.

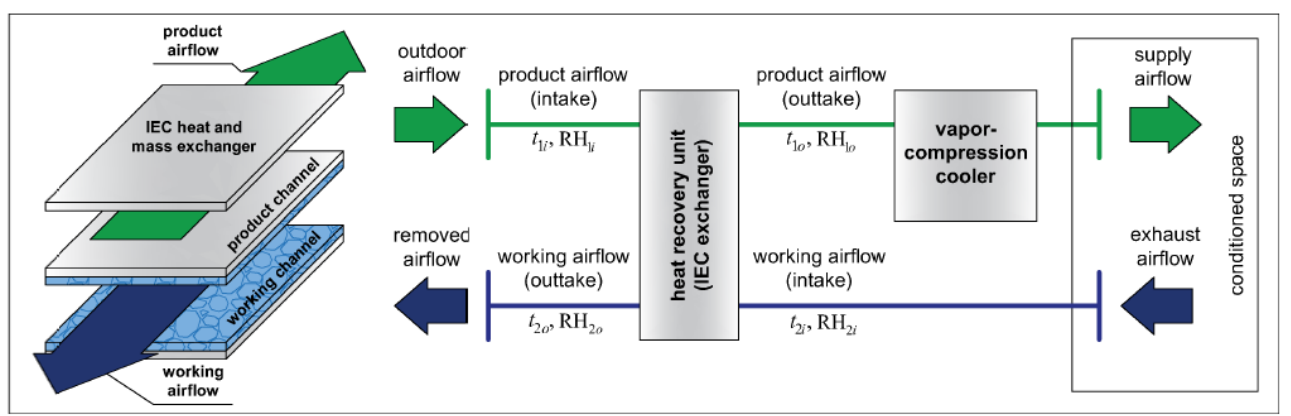

Fig. 1. Scheme of the AC system consisted of the heat recovery unit in a counter-flow configuration and conventional vapour-compression unit ( 1 - product airflow; 2 - working airflow; $i$ - inlet; $o-$ outlet).

\section{Methods}

The heat and mass transfer processes in the counter-flow IEC exchanger are described with $\varepsilon-\mathrm{NTU}$ model. Model accuracy is verified with an experimentally validated model by Cui et al. [7]. 


\subsection{Mathematical model}

Heat and mass balance was calculated under steady-state operation with ordinary differential equations. The developed equations describing the heat and mass transfer in the counter-flow IEC exchanger is nonlinear and cannot be solved analytically, therefore the numerical methods were implemented. Numerical simulations were performed with modified Runge-Kutta method, that proved to be at sufficient accuracy with similar problems $[8,9]$. The condensation process is taken into consideration when product channel plate surface temperature is lower than the product airflow dew-point temperature. The heat conservation balance for the product airflow is described with Eq. (1) for non-condensation state, and with Eq. (2) for the condensation sate.

$$
\begin{aligned}
& \frac{d t_{1}}{d \bar{X}}=\mathrm{NTU}_{1}\left(t_{p 1}-t_{1}\right) \\
& \frac{d t_{1}}{d \bar{X}}=\mathrm{NTU}_{1}\left(t_{p 1}^{\prime}-t_{1}\right)
\end{aligned}
$$

where: $t$ - temperature, ${ }^{\circ} \mathrm{C}$; NTU - number of transfer units, $-; X$ - coordinate along product airflow direction, $\mathrm{m}$. Subscripts: ' - condition at the air/plate interface; 1 - related to product channel; $p$ - plate surface.

The mass conservation balance under condensation state for the product airflow is described with Eq. (3).

$$
\frac{d x_{1}}{d \bar{X}}=\operatorname{NTU}_{1}\left(\frac{\sigma_{p}}{\operatorname{Le}}\right)_{1}\left(x_{p 1}^{\prime}-x_{1}\right)
$$

where: $x$ - humidity ratio of moist air, $\mathrm{kg} / \mathrm{kg} ; \sigma$ - surface wettability factor, -; Le Lewis factor.

For the working channel, the heat conservation balance is described with Eq.(4). The mass conservation balance for the water vapour inside the working channel is described by Eq. (5).

$$
\begin{gathered}
\frac{d t_{2}}{d \bar{X}}=-\mathrm{NTU}_{2}\left(t_{p 2}^{\prime}-t_{2}\right)\left[1+\left(\frac{\sigma_{p}}{\mathrm{Le}}\right)_{2}\left(\frac{c_{g}}{c_{p}}\right)_{2}\left(x_{p 2}^{\prime}-x_{2}\right)\right] \\
\frac{d x_{2}}{d \bar{X}}=-\mathrm{NTU}_{2}\left(\frac{\sigma_{p}}{\mathrm{Le}}\right)_{2}\left(x_{p 2}^{\prime}-x_{2}\right)
\end{gathered}
$$

where: $c_{g}$ - specific heat capacity of water vapor, $\mathrm{J} /(\mathrm{kgK}) ; c_{p}$ - specific heat capacity of moist air, $\mathrm{J} /(\mathrm{kgK})$. Subscripts: 2 - related to working channel.

Additional energy balance equations are introduced for non-condensation (Eq. (6)) and condensation state (Eq. (7)).

$$
\frac{d t_{1}}{d \bar{X}}-\left(\frac{W_{2}}{W_{1}}\right)\left[\frac{d t_{2}}{d \bar{X}}+\frac{\left(r^{0}+c_{g 2} t_{2}\right)-c_{w 2} t_{p 2}^{\prime}}{c_{p 2}} \frac{d x_{2}}{d \bar{X}}\right]=0
$$




$$
\left[\frac{d t_{1}}{d \bar{X}}+\frac{\left(r^{\mathrm{o}}+c_{g 1} t_{1}\right)-c_{w 2} t_{p 1}^{\prime}}{c_{p 1}} \frac{d x_{1}}{d \bar{X}}\right]-\left(\frac{W_{2}}{W_{1}}\right)\left[\frac{d t_{2}}{d \bar{X}}+\frac{\left(r^{\mathrm{o}}+c_{g 2} t_{2}\right)-c_{w 2} t_{p 2}^{\prime}}{c_{p 2}} \frac{d x_{2}}{d \bar{X}}\right] \approx 0
$$

where: $W$ - heat capacity rate of the fluid, $\mathrm{W} / \mathrm{K} ; r^{0}$ - specific heat of water evaporation at the temperature $0^{\circ} \mathrm{C}, \mathrm{kJ} / \mathrm{kg} ; c_{w}$ - specific heat capacity of water, $\mathrm{J} /(\mathrm{kgK})$.

Differential equations presented above are supplemented with initial conditions of the product and working airflow at the intake to the corresponding channels (Eq. (8)) and with the set of boundary conditions describing the plate surface in the product channel, considering the water vapour condensation from product airflow (Eq. (9)).

$$
\begin{gathered}
t_{1} \mid \begin{array}{l}
=t_{1 i} \\
X_{1}=0
\end{array} ; \quad \begin{array}{l}
x_{1}\left|\begin{array}{l}
=x_{1 i} \\
X_{1}=0
\end{array} ; t_{2}\right| \begin{array}{l}
=t_{2 i} \quad \\
X_{2}=0
\end{array} ; \begin{array}{l}
x_{2} \mid=x_{2 i} \\
X_{2}=0
\end{array} \\
\sigma_{p 1}\left|\begin{array}{l}
=0 \\
t_{p 1}>t_{1}^{D P}
\end{array} ; \sigma_{p 1}\right| \begin{array}{l}
=1 \\
t_{p 1} \leq t_{1}^{D P}
\end{array} ; x_{p 1}^{\prime}\left|\begin{array}{l}
=x_{1} \\
t_{p 1}>t_{1}^{D P}
\end{array} ; \quad x_{p 1}^{\prime}\right|=x_{p 1}^{s a t} \\
t_{p 1} \leq t_{1}^{D P}
\end{array}
\end{gathered}
$$

\subsection{Mathematical model validation}

The mathematical model accuracy under condensation state is verified with experimentally validated model presented by Cui et al. [7]. It is found that the presented model shows average discrepancy equals to $2.4 \%$ in terms of outlet temperature and $3.2 \%$ for outlet humidity ratio. Detailed validation results are listed in Table 1 . Based on the model validation, it is concluded that presented model is able to predict counter-flow IEC exchanger performance with good approximation under condensation and noncondensation state.

Table 1. Mathematical model validation against results from recent published paper [7].

\begin{tabular}{|l|c|c|c|c|c|c|}
\hline \multirow{2}{*}{$\begin{array}{l}\text { Inlet } \\
\text { temperature, } \\
{ }^{\circ} \mathrm{C}\end{array}$} & $\begin{array}{c}\text { Outlet temperature, } \\
\text { Cui et al } \\
{[7]}\end{array}$ & $\begin{array}{c}\text { Present } \\
\text { study }\end{array}$ & Error & $\begin{array}{c}\text { Cui et al } \\
{[7]}\end{array}$ & $\begin{array}{c}\text { Present } \\
\text { study }\end{array}$ & Error \\
\hline $\mathrm{RH}=70 \%$ & 21.9 & 22.3 & $\mathbf{2 . 0 \%}$ & 16.6 & 16.5 & $\mathbf{0 . 7 \%}$ \\
\hline 30.0 & 23.1 & 23.6 & $\mathbf{2 . 3 \%}$ & 17.9 & 17.9 & $\mathbf{0 . 1 \%}$ \\
\hline 32.5 & 24.9 & 25.0 & $\mathbf{0 . 4 \%}$ & 19.9 & 19.6 & $\mathbf{1 . 8 \%}$ \\
\hline 35.0 & 27.0 & 26.4 & $\mathbf{2 . 1 \%}$ & 22.6 & 21.4 & $\mathbf{5 . 4 \%}$ \\
\hline 37.5 & 23.6 & 23.7 & $\mathbf{0 . 5 \%}$ & 18.3 & 18.7 & $\mathbf{2 . 1 \%}$ \\
\hline $\mathrm{RH}=90 \%$ & 25.6 & 25.2 & $\mathbf{1 . 4 \%}$ & 20.9 & 20.6 & $\mathbf{1 . 3 \%}$ \\
\hline 30.0 & 27.9 & 26.7 & $\mathbf{4 . 3 \%}$ & 23.9 & 22.6 & $\mathbf{5 . 3 \%}$ \\
\hline 32.5 & 30.3 & 28.3 & $\mathbf{6 . 7 \%}$ & 27.6 & 25.0 & $\mathbf{9 . 3 \%}$ \\
\hline 35.0 &
\end{tabular}

\section{Results and discussion}

In this section simulations results are presented and discussed. Proposed AC system is presented in Figure 1. Simulations were carried out for selected values of the working and product airflow inlet parameters that can be observed in the moderate climates. Inlet airflow parameters used in numerical simulations and characteristic dimensions of the IEC exchanger are listed in Table 2. Similar simulation are carried out for the conventional recuperation unit with temperature effectiveness $\varepsilon_{t}=0.8$. 
Table 2. Characteristic parameters of the IEC exchanger and inlet airflow parameters.

\begin{tabular}{|l|c|}
\hline Parameters & Present study \\
\hline Wall thickness, mm & 0.3 \\
\hline Channel length/width/height, $\mathrm{m}$ & $0.5 / 0.5 / 0.003$ \\
\hline Working to intake air ratio & 1 \\
\hline Product air temperature, ${ }^{\circ} \mathrm{C}$ & $28-34$ \\
\hline Product air relative humidity, $\%$ & $40-60$ \\
\hline Working air temperature, ${ }^{\circ} \mathrm{C}$ & $22-26$ \\
\hline Working air relative humidity, $\%$ & $40-60$ \\
\hline
\end{tabular}

In this study, different performance indicators were used in order to evaluate the heat recovery unit performance:

- Temperature drop for the product airflow: $\Delta t_{1}=t_{1 i}-t_{1 o},{ }^{\circ} \mathrm{C}$

- Humidity ratio drop for the product airflow: $\Delta x_{1}=x_{1 i}-x_{1 o}, \mathrm{~g} / \mathrm{kg}$

\subsection{Comparison between IEC heat and mass exchanger and conventional recuperator}

Under moderate climate conditions water vapour condensation from product airflow usually occurs only at some part of the product channel or it does not occur at all. Under non-condensation state, the product airflow is sensibly cooled without change in its moisture content. Under partial condensation state, the sensible cooling and additional dehumidification of the product airflow takes place. The condensation occurs when plate temperature is lower than the dew-point temperature of the product air, which is possible when units operates on the exhaust airflow with low temperature and humidity. The exemplary processes in the product (process $1 i-1 o$ ) and working channel (process $2 i-2 o$ ) in the IEC exchanger (Fig. 2(a)) and corresponding processes in the conventional recuperator with thermal effectiveness $\varepsilon_{t}=0.8$ (Fig. 2(b)) are presented on the psychrometric charts.

(a)

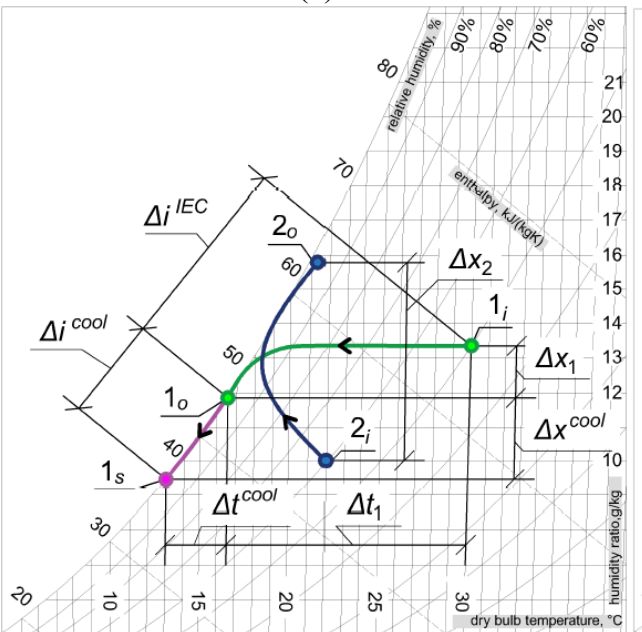

(b)

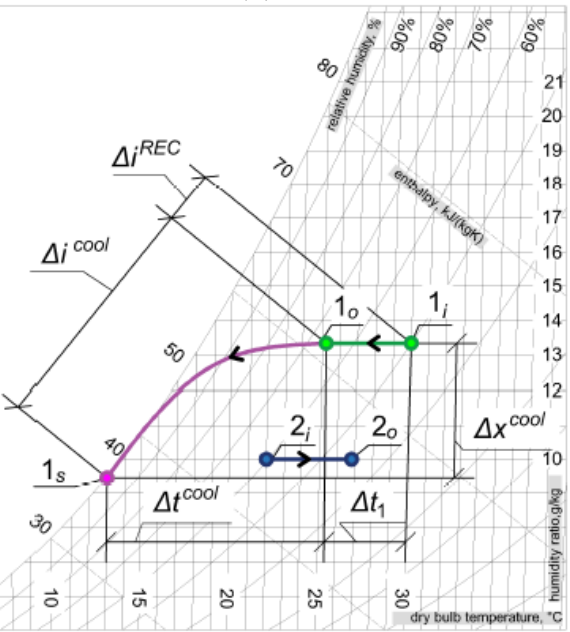

Fig. 2. Psychrometric chart that represents the AC system with vapor-compression cooler and heat recovery unit: (a) counter-flow IEC heat and mass exchanger (NTU=4.0); (b) counter-flow recuperator with temperature effectiveness $\varepsilon_{t}=0.8(1$ - product channel; 2 - working channel; $i$ - inlet parameters; $o$ - outlet parameters; $s$ - supply; cool-vapor-compression cooler, $R E C$ - recuperation). 


\subsubsection{Performance comparison for different inlet product airflow parameters}

Performance indicators achieved for different temperature and relative humidity of the product airflow are presented in Figure 3. It can be concluded that $\Delta t_{1}$ increases with increased product airflow temperature (Fig. 3(a)). It is due to the higher temperature difference between product airflow and the plate surface. With increased product airflow humidity, the $\Delta t_{1}$ value is lowering while the $\Delta x_{1}$ is increasing (Fig. 3(a) and (b)). It is related with more intense condensation process when the product airflow humidity is higher. With water vapour condensation, the additional amount of latent heat is released, which causes increase in the plate temperature. This, in turn, leads to decreased sensible heat transfer rate. It can also be seen, that while no condensation occurs (like in case of $t_{1 i}=28^{\circ} \mathrm{C}$ and $\mathrm{RH}_{1 i}=40 \%$ and $45 \%$ ), the $\Delta t_{1}$ remains the same.

For conventional recuperator, $\Delta t_{1}$ depends only on the product airflow temperature. Comparing with IEC exchanger, $\Delta t_{1}$ is on average 3.1 (for $t_{1 i}=28^{\circ} \mathrm{C}$ ) to 1.8 (for $t_{1 i}=34^{\circ} \mathrm{C}$ ) times lower. While there is no condensation in the case of conventional recuperation, the $\Delta x_{1}$ is equal to zero and therefore no additional energy savings on dehumidification can be obtained. The detailed analysis of potential energy savings achieved by applying an IEC unit instead of a conventional recuperator is given in a further section.

(a)

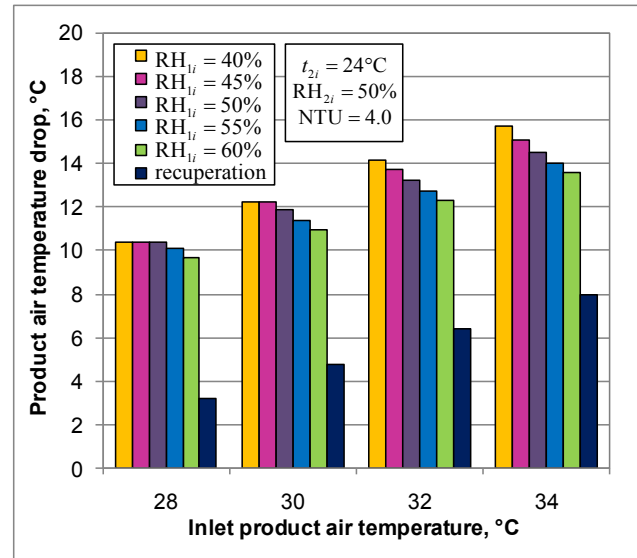

(b)

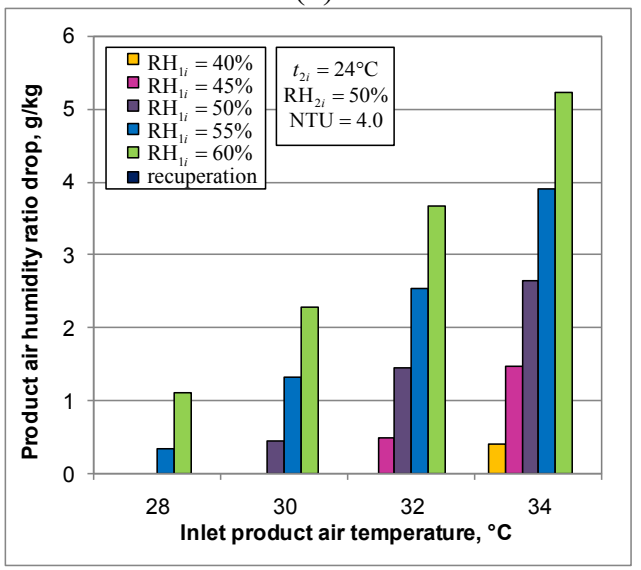

Fig. 3. Performance indicators of the heat recovery unit for different inlet product airflow parameters: (a) product air temperature drop; (b) product air humidity ratio drop.

\subsubsection{Performance comparison for different inlet working airflow parameters}

Performance indicators achieved for different temperature and relative humidity of the working airflow are presented in Figure 4. In considered cases, the highest sensible (the highest $\Delta t_{1}$ ) and latent cooling potential (the highest $\Delta x_{1}$ ) has the working airflow with lowest temperature and lowest relative humidity (Fig. 4(a) and (b)). For the same inlet working airflow temperature, working airflow with lower humidity has higher cooling potential. For example, at the same temperature of $t_{2 i}=22^{\circ} \mathrm{C}$, the $\Delta t_{1}$ value is $2.5^{\circ} \mathrm{C}$ lower for $\mathrm{RH}_{2 i}=40 \%$ than for $\mathrm{RH}_{2 i}=60 \%$ (Fig. 4(a)). For conventional recuperation, the $\Delta t_{1}$ value is on average 2.0 (for $t_{2 i}=22^{\circ} \mathrm{C}$ ) and 3.5 (for $t_{2 i}=26^{\circ} \mathrm{C}$ ) times lower than for IEC exchanger. According to changes in $\Delta x_{1}$ values, the lower is the temperature and relative humidity of the working airflow, the process of condensation in the product channel is more likely to occur. For some working airflow parameters, the process of condensation may not appear at all (Fig. 4(b)). 
(a)

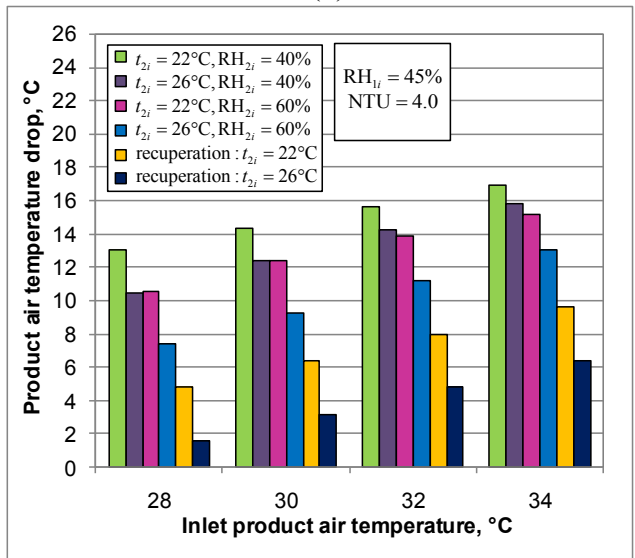

(b)

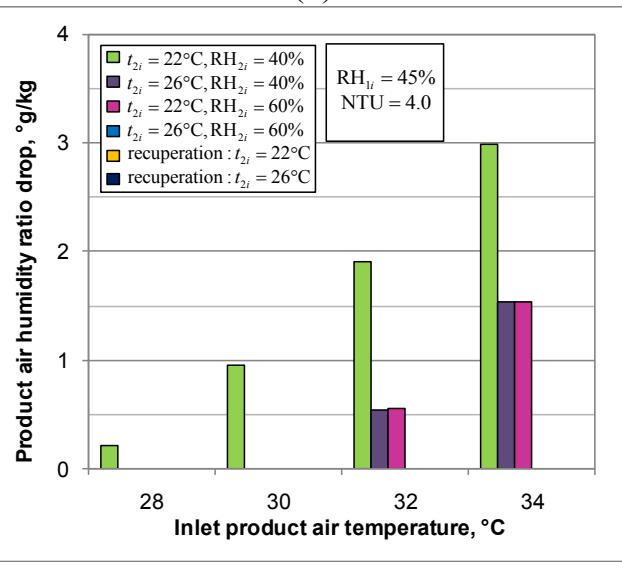

Fig. 4. Performance indicators of the heat recovery unit for different inlet working airflow parameters: (a) product air temperature drop; (b) product air humidity ratio drop.

\subsection{Comparison between the AC system with IEC heat and mass exchanger and conventional recuperator}

In this section, the AC system with counter-flow IEC heat and mass exchanger used as a heat recovery unit is compared with standard AC system with counter-flow heat recuperation device with temperature effectiveness $\varepsilon_{t}=0.8$. The proposed $\mathrm{AC}$ system is presented in Figure 1. To compare different heat recovery techniques, the constant supply airflow temperature is set at $t_{1 s}=13^{\circ} \mathrm{C}$ and relative humidity at $\mathrm{RH}_{1 s}=100 \%$. In order to make a comparison, the overall temperature drop, humidity ratio drop and cooling capacity required by the $\mathrm{AC}$ system is calculated for the inlet product and working airflow parameters presented in Table 3. The cooling capacity for IEC exchanger is calculated with Eq. (10) and for recuperator with Eq.(11). The percentage of the air-conditioning system requirements that can be covered by the IEC exchanger and by the recuperation unit are listed in Table 3.

$$
\begin{aligned}
& Q_{1}=V \cdot \rho \cdot\left(i_{1 i}-i_{1 o}\right), \mathrm{kW} ; \mathrm{V}=1000 \mathrm{~m}^{3} / \mathrm{h} \\
& Q_{1}^{R E C}=V \cdot \rho \cdot c_{p} \cdot \Delta t_{1}, \mathrm{~kW} ; \mathrm{V}=1000 \mathrm{~m}^{3} / \mathrm{h}
\end{aligned}
$$

In most considered cases, the IEC exchanger allows to cover a significant part of the airconditioning system requirements in compare with standard recuperation unit. It can be seen that on average $11 \%$ of required dehumidification process can be realized in the IEC exchanger, which is the additional advantage over the recuperation where condensation does not occur (Tab. 3). In terms of cooling capacity, the IEC exchanger covers on average $43 \%$ of the AC system cooling load while a standard recuperation unit is able to realize only $18 \%$ of required cooling. Another important notice is that water condensing on the plate of IEC exchanger summarized with water condensed in cooling coil can be reused and supplied to the working channel. This allows to save significant amount of water which normally would be supplied from the grid. It is found that on average $79 \%$ of water requirements can be restored from condensation. For certain parameters (i.e. $t_{2 i}=26^{\circ} \mathrm{C}$, $\mathrm{RH}_{2 i}=60 \%$ and $t_{1 i}=32^{\circ} \mathrm{C}$ ) it is possible to provide full water supply of the IEC exchanger with condensate, so that additional water supply from external network is not required. 
Table 3. Percentage of the required humidity ratio drop, cooling capacity and water requirements covered by the IEC exchanger (NTU=4.0) or conventional counter-flow recuperator with $\varepsilon_{t}=0.8$.

\begin{tabular}{|c|c|c|c|c|}
\hline \multirow{2}{*}{$\begin{array}{l}t_{1 i},{ }^{\circ} \mathrm{C} \\
\mathrm{RH}_{1 i}=50 \%\end{array}$} & \multicolumn{2}{|c|}{$t_{2 i}=22^{\circ} \mathrm{C}, \mathrm{RH}_{2 i}=60 \%$} & \multicolumn{2}{|c|}{$t_{2 i}=26^{\circ} \mathrm{C}, \mathrm{RH}_{2 i}=60 \%$} \\
\hline & IEC & Recuperation & IEC & Recuperation \\
\hline \multicolumn{5}{|c|}{ Required humidity ratio drop coverage } \\
\hline 28 & $0 \%$ & $0 \%$ & $0 \%$ & $0 \%$ \\
\hline 30 & $13 \%$ & $0 \%$ & $0 \%$ & $0 \%$ \\
\hline 32 & $27 \%$ & $0 \%$ & $0 \%$ & $0 \%$ \\
\hline 34 & $37 \%$ & $0 \%$ & $11 \%$ & $0 \%$ \\
\hline \multicolumn{5}{|c|}{ Required cooling capacity coverage } \\
\hline 28 & $50 \%$ & $22 \%$ & $34 \%$ & $7 \%$ \\
\hline 30 & $50 \%$ & $23 \%$ & $34 \%$ & $12 \%$ \\
\hline 32 & $52 \%$ & $24 \%$ & $34 \%$ & $14 \%$ \\
\hline 34 & $54 \%$ & $24 \%$ & $37 \%$ & $16 \%$ \\
\hline \multicolumn{5}{|c|}{ Required water supply coverage } \\
\hline 28 & $50 \%$ & $\mathrm{n} / \mathrm{a}$ & $57 \%$ & $\mathrm{n} / \mathrm{a}$ \\
\hline 30 & $69 \%$ & $\mathrm{n} / \mathrm{a}$ & $80 \%$ & $\mathrm{n} / \mathrm{a}$ \\
\hline 32 & $82 \%$ & $\mathrm{n} / \mathrm{a}$ & $102 \%$ & $\mathrm{n} / \mathrm{a}$ \\
\hline 34 & $92 \%$ & $\mathrm{n} / \mathrm{a}$ & $114 \%$ & $\mathrm{n} / \mathrm{a}$ \\
\hline
\end{tabular}

\section{Summary and conclusions}

In this paper, performance studies of the counter-flow IEC heat and mass exchanger applied as a heat recovery device are presented. Studies are carried out for selected values of the inlet working and product airflow parameters which can be observed in the moderate climate conditions. Numerical simulations were performed with validated analytical $\varepsilon-\mathrm{NTU}$ model. It was concluded that the IEC exchanger, employed as a heat recovery device, allows to obtain higher performance indicators than conventional heat recuperation unit.

One of the co-authors, Demis Pandelidis, received financial support for his research from resources for scientific work for years 2016-2019 from Polish Ministry of Science and High Education (program "Iuventus Plus"), project number IP2015 058274.

\section{References}

1. B. Porumb, M. Bălan, R. Porumb, Energy Procedia 85, 433-441 (2016)

2. Z. Duan, C. Zhan, X. Zhang, M. Mustafa, X. Zhao, B. Alimohammadisagvand, A. Hasan, Renewable and Sustainable Energy Reviews 16, Issue 9, 6823-6850 (2012)

3. Y. Wan, C. Ren, L. Xing, Int. J. Heat Mass Tran. 108 Part B, 1750-1763 (2017)

4. Z. Duan, C. Zhan, X. Zhao, X. Dong, Building and Environment 104, 47-58 (2016)

5. Z. Duan, X. Zhao, C. Zhan, X. Dong, H. Chen, Energ. Buildings 148, 199-210 (2017)

6. Y. Chen, Y. Luo, H. Yang, Energ. Buildings 108, 387-400 (2015)

7. X. Cui, K.J. Chua, M.R. Islam, K.C. Ng, Energ. Convers. Manage. 102, 140-150 (2015)

8. S. Anisimov, D. Pandelidis, Int. J. Heat Mass Tran. 75, 75-96 (2014)

9. S. Anisimov, D. Pandelidis, International Journal of Energy for a Clean Environment ("Special Issue on M-Cycle Fundamentals and Applications") 12 Issue 2-4, 239-250 (2011) 